\title{
Plastic Shrinkage Cracking in Concrete ${ }^{\dagger}$
}

\author{
Faez Sayahi *, Mats Emborg, Hans Hedlund and Andrzej Cwirzen \\ Department of Civil, Environmental and Natural Resources Engineering, Luleå University of Technology, \\ 97187 Luleå, Sweden; mats.emborg@ltu.se (M.E.); hans.hedlund@ltu.se (H.H.); andrzej.cwirzen@ltu.se (A.C.) \\ * Correspondence: faez.sayahi@ltu.se \\ + Presented at the 1st International Conference on Smart Materials for Sustainable Construction-SMASCO \\ 2019, Luleå, Sweden, 10-12 December 2019.
}

Published: 18 November 2019

\begin{abstract}
Plastic shrinkage cracking in concrete is mainly a physical process, in which chemical reactions between cement and water do not play a decisive role. It is commonly believed that rapid and excessive moisture loss, due to evaporation is the primary cause of the phenomenon. Once the concrete is cast, its solid particles start to settle due to gravity, causing an upward water-flow from the concrete interior and through its pore system to the surface, i.e., bleeding regime. When the amount of the evaporated water exceeds the amount of the water accumulated at the concrete surface, i.e., bleed water, concrete enters the so called drying regime, during which water menisci form inside the pores causing a build-up of a negative pore pressure, also known as capillary pressure. The progressive evaporation gradually decreases the radii of the menisci, which causes a further increase of the pore pressure and solid particles consolidation. Eventually, the skeleton of the concrete becomes stiff enough to resist the gravitational forces, which means that the vertical deformation of the concrete either completely stops or continues at a much lower rate. At this point, the capillary pressure is no longer able to further consolidate the concrete and move the pore water towards the surface. Instead, the developed tensile forces reduce the inter particle distances and the horizontal deformation continues. If the concrete member is restrained (e.g., due to reinforcement, variation in sectional depth, the friction of the form, etc.), the shrinkage can lead to tensile stresses accumulation. Once the tensile stresses exceed the early age tensile strength of the concrete, cracks start to form, preparing passageways for ingress of harmful materials into the concrete interior, which eventually may impair the durability and serviceability of the structure. This abstract reports the findings of a PhD research, carried out at Luleå University of Technology (LTU) to investigate the impact of parameters such as, admixtures, water-cement ratio (w/c), cement type, dosage of superplasticizer (SP), and steel fibers, on concrete's cracking tendency while in plastic state. The results show that presence of accelerators, retarders, coarser cement particles, high w/c, and more $\mathrm{SP}$ increases the cracking risk, while stabilizers, air entraining agents (AEA), shrinkage reducing admixtures (SRA), and steel fibers notably decrease the cracking potential. Based on the findings of the above mentioned investigation a new model is proposed to estimate the severity of plastic shrinkage cracking, based on the initial setting time and the amount of the evaporated water from within the concrete bulk. The experimental results of the $\mathrm{PhD}$ research, alongside those reported by other researchers, were utilized to check the validity of the proposed model. According to the outcomes, the model could predict the cracking severity of the tested concretes with a good precision.
\end{abstract}


Keywords: plastic shrinkage; cracking; admixtures; cement type; water-cement ratio; settlement; evaporation; bleeding; capillary pressure

(C) 2019 by the authors. Licensee MDPI, Basel, Switzerland. This article is an open access article distributed under the terms and conditions of the Creative Commons Attribution (CC BY) license (http://creativecommons.org/licenses/by/4.0/). 